\title{
Computational Fluid Dynamics Simulation of Oxygen Seepage in Coal Mine Goaf with Gas Drainage
}

\author{
Guo-Qing Shi, ${ }^{1}$ Mao-xi Liu, ${ }^{1}$ Yan-Ming Wang, ${ }^{2}$ Wen-Zheng Wang, ${ }^{1}$ and De-Ming Wang ${ }^{1}$ \\ ${ }^{1}$ School of Safety Engineering, China University of Mining and Technology, Xuzhou 221116, China \\ ${ }^{2}$ Department of Mechanical and Aerospace Engineering, Rutgers, The State University of New Jersey, Piscataway, NJ 08854, USA \\ Correspondence should be addressed to Yan-Ming Wang; cumtwangym@163.com
}

Received 7 August 2014; Revised 17 October 2014; Accepted 27 October 2014

Academic Editor: Shaofan Li

Copyright (c) 2015 Guo-Qing Shi et al. This is an open access article distributed under the Creative Commons Attribution License, which permits unrestricted use, distribution, and reproduction in any medium, provided the original work is properly cited.

\begin{abstract}
Mine fires mainly arise from spontaneous combustion of coal seams and are a global issue that has attracted increasing public attention. Particularly in china, the closure of coal workfaces because of spontaneous combustion has contributed to substantial economic loss. To reduce the occurrence of mine fires, the spontaneous coal combustion underground needs to be studied. In this paper, a computational fluid dynamics (CFD) model was developed for coal spontaneous combustion under goaf gas drainage conditions. The CFD model was used to simulate the distribution of oxygen in the goaf at the workface in a fully mechanized cave mine. The goaf was treated as an anisotropic medium, and the effects of methane drainage and oxygen consumption on spontaneous combustion were considered. The simulation results matched observational data from a field study, which indicates CFD simulation is suitable for research on the distribution of oxygen in coalmines. The results also indicated that near the workface spontaneous combustion was more likely to take place in the upper part of the goaf than near the bottom, while further from workface the risk of spontaneous combustion was greater in the lower part of the goaf. These results can be used to develop firefighting approaches for coalmines.
\end{abstract}

\section{Introduction}

Spontaneous combustion of coal is an issue that threatens the development of the coal industry worldwide. Among China's state-owned collieries, $56 \%$ of the mines have been jeopardized by spontaneous combustion, and the combustion incidents in these mines account for $90-94 \%$ of all coalmine fires [1]. Since the 1990s, the coalmines operating in China have mainly been fully mechanized cave mines. This type of mining leaves a large amount coal in the goaf. The production efficiency is increased compared to nonmechanized mining, but fully mechanized mining results in high air leakage, high rock fall, and more loose coal. These factors increase the probability of coal spontaneous combustion. Furthermore to reduce the risks of gas explosion and improve utilization of methane, especially in mines with high gas content, at some coalmines gas is drained from the mine goaf and coal with high negative pressure technology. These practices increase the air leakage volume and disturb mine ventilation, which elevates the risk of coal spontaneous combustion.
Spontaneous combustion of coal underground takes place mainly in the goaf and occurs through a complex system of thermal, hydraulic, chemical, and mechanical processes [2-6]. The combustion of coal underground is closely related to the concentration and distribution of oxygen in the goaf [7]. Consequently, study of the oxygen concentration and distribution is important to understand coal spontaneous combustion. To date, the oxygen distribution in coal mine goaf has typically been approximated from either a minimal number of actual gas measurements in the goaf or model test results obtained in the laboratory. These two methods have many disadvantages, one of which is the heavy workload required. Although laboratory results are valuable, their extrapolation to the mining environment is not entirely successful because scaling is complicated, and small-scale experiments do not accurately replicate the largescale environment. Scaling issues typically arise when the coal temperature is high enough that radiative heat transfer cannot be neglected. In these cases, there are problems with scaling of the radiative heat transfer from the small-scale 
spontaneous combustion results to large-scale mining. For small-scale tests when the coal temperature is low, radiative heat transfer can be neglected but the test results have not been validated $[7,8]$. Consequently, it is necessary to establish a new method to study coal spontaneous combustion.

In this paper, to study coal spontaneous combustion, we developed a three-dimensional CFD model of the oxygen concentration under conditions of gas drainage from the goaf. The distribution of oxygen in the goaf was simulated, and the results used to evaluate the coal spontaneous combustion hazard in specific areas of the goaf. The influence of goaf gas drainage on oxygen distribution was also studied using numerical methods. The results could be used for prevention of coal spontaneous combustion and to establish fire-fighting protocols.

\section{Theory}

2.1. Oxygen Diffusion in the Goaf. In order to simulate the oxygen distribution in goaf under gas drainage conditions, numerical modeling was performed with CFD theories. The finite volume method with the second-order upwind scheme was used to solve the coupled flow, mass transfer, and energy equations using the CFD solver. CFD simulations require solving the Navier-Stokes (N-S) equations, which are formed from a series of partial differential equations governing mass, momentum, and energy conservation. If mass transfer and mixing are part of the process under investigation, then a conservation equation for the components must also be included [9]. The mathematical model for flow of mixed gas in the mine goaf is developed using these equations, along with specific boundary conditions and initial conditions. The following equations apply to gas flow in goaf [10]. The mass conservation equation can be expressed as

$$
\frac{\partial \rho}{\partial t}+\frac{\partial\left(\rho u_{i}\right)}{\partial x_{i}}=s_{m}
$$

where $\rho$ is the density the mixed gas, $i$ represents the $x, y, z$ coordinates in three-dimensional space, $x_{i}$ is the distance, $t$ is the time, $u_{i}$ is the velocity, and $s_{m}$ is the source of mass loss of gas in goaf.

The momentum conservation equation is

$$
\frac{\partial}{\partial t}\left(\rho u_{i}\right)+\frac{\partial}{\partial x_{j}}\left(\rho u_{i} u_{j}\right)=-\frac{\partial p}{\partial x_{i}}+\frac{\partial \tau_{i j}}{\partial x_{j}}+\rho g_{i}+s_{i},
$$

where $p$ is the gas pressure of cube $i, j$ represents the $x, y$, $z$ coordinates in three-dimensional space, $x_{j}$ is the distance, $\tau_{i j}$ is the viscous stress tensor which is caused by the viscous effect, $g_{i}$ is the gravity component in direction $i$, and $s_{i}$ is source of momentum loss. The momentum loss is caused by fluid flow in porous media and can be expressed as

$$
s_{i}=\sum_{j=1}^{3} D_{i j} \mu v_{j}+\sum_{j=1}^{3} C_{i j} \frac{1}{2} \rho\left|v_{j}\right| v_{j},
$$

where $\mu$ is the gas viscosity in the goaf; $D_{i j}$ is the matrix of the viscous loss coefficient; $C_{i j}$ is the matrix of the inertia loss coefficient; and $v_{j}$ is the velocity component in direction $j$, where $j$ represents the $x, y, z$ coordinates in threedimensional space. This equation indicates that when the velocity is low in comparison to the viscous loss coefficient, the inertia loss coefficient will be infinitely small.

Equation (3) is equivalent to Darcy's equation. Convection and diffusion of the multicomponent gas is mainly considered when air transfer occurs in the goaf. From the component mass conservation law, the following conservation equation is obtained:

$$
\frac{\partial\left(\rho c_{S}\right)}{\partial t}+\operatorname{div}\left(\rho \vec{u} c_{S}\right)=\operatorname{div}\left(D_{S} \operatorname{grad}\left(\rho c_{S}\right)\right)+s_{S}
$$

where $c_{S}$ is the fraction of component $S$ and $\rho$ is its density, $D_{S}$ is the diffusion coefficient of component $S, s_{S}$ is the source term of $S$, and $\operatorname{div}(*)=\partial a_{x} / \partial x+\partial a_{y} / \partial y+\partial a_{z} / \partial z$ is a scalar quantity. The source term includes events such as methane and $\mathrm{CO}$ release and oxygen consumption.

The energy transport equation is formulated under the assumption of thermal equilibrium between the solid matrix and gas. Coal oxidation is an exothermic process, and to provide an accurate description of oxygen concentration, the link between heat production and oxygen consumption must be considered. Therefore, the mathematical model should contain energy conservation equations such as

$$
\frac{\partial(\rho T)}{\partial t}+\operatorname{div}(\rho \vec{u} T)=\operatorname{div}\left(\frac{k}{c_{p}} \operatorname{grad} T\right)+s_{T},
$$

where $c_{p}$ is the specific heat capacity, $T$ is the thermodynamic temperature, $k$ is the thermal conductivity of gas in the goaf, and $s_{T}$ is energy source term. For CFD simulation, the geometry, material properties, and boundary conditions need to be specified.

2.2. CFD Model of Oxygen for the Fully Mechanized Cave Mine Workface. The distribution of oxygen was modeled using the widely used CFD software FLUENT. CFD analysis generally involves the following key steps: field studies to obtain basic information on goaf geometry and other parameters; meshing of the established geometric model to a finite element grid by automatic mesh generation software such as Gambit; establishment of flow models and boundary conditions through user-defined functions (UDFs) as described in [11]; model simulations with basic conditions; model calibration and validation with field measured data; and study of the influence of various parameters on the oxygen distribution using the CFD model.

The main factors influencing the distribution of oxygen in mine goaf are viscous flow, which is caused by a pressure gradient, and diffusion, which is caused by a concentration gradient. The longwall goaf permeability and oxygen consumption and diffusion coefficients are the main parameters in a mathematical model of oxygen distribution. Goaf permeability is largely affected by the distribution of pressure in the goaf. Creedy and Clarke highlighted that the permeability at the edge of the goaf is significantly different from that in the middle, and the permeability in these areas 


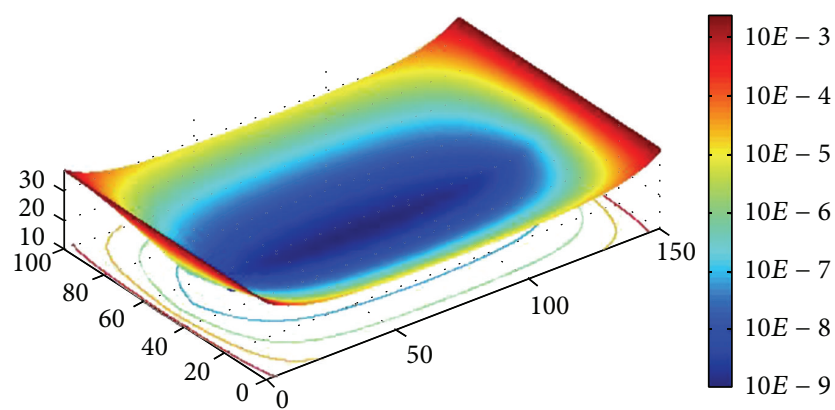

Figure 1: Permeability distributions in the goaf.

can range from $10^{-2} \mathrm{~m}^{2}$ to $10^{-7} \mathrm{~m}^{2}$ [12]. In the simulation in the present study, goaf permeability was varied from $10^{-2} \mathrm{~m}^{2}$ to $10^{-9} \mathrm{~m}^{2}$, and the permeability was expressed by a hyperbolic tangent function $[13,14]$, and the characteristics of permeability distribution can be seen as in Figure 1.

With Fick's Law of diffusion, the diffusion flux can be expressed by the following equation [15]:

$$
J_{i}=\rho D_{i m} \frac{\partial X_{i}}{\partial x_{i}}-\frac{D_{i}^{T}}{T} \frac{\partial T}{\partial x_{i}}
$$

where $J_{i}$ is diffusion flow volume of gas $i$ and is mainly caused by concentration and thermal gradients; $D_{i m}$ is the diffusion coefficient of the mixed gas; $x_{i}$ is mass fraction of gas $i ; D_{i}^{T}$ is the thermal diffusion, and $T$ is the temperature.

For a nonrarefied gas, (5) can be replaced by the following equation:

$$
J_{i}=\rho \frac{M_{i}}{M_{\min }} \sum_{j, j \neq i} D_{i j}\left(\frac{\partial X_{j}}{\partial x_{i}}+\frac{X_{j}}{M_{\operatorname{mix}}} \frac{\partial M_{\mathrm{mix}}}{\partial x_{i}}\right)-\frac{D_{i}^{T}}{T} \frac{\partial T}{\partial x_{i}},
$$

where $M_{i}$ is the molecular weight of gas $i, M_{\min }$ is the molecular weight of the mixed gas, and $D_{i j}$ is the diffusion coefficient of gas $i$ mixed with gas $j$.

The chemical reaction between coal and oxygen at low temperatures is complex. Generally, the following three types of processes are believed to occur [16]: (i) physical adsorption; (ii) chemical adsorption, which leads to the formation of coal-oxygen complexes and oxygenated carbon species; and (iii) oxidation, in which the coal and oxygen react and release gaseous products such as carbon monoxide (CO), carbon dioxide $\left(\mathrm{CO}_{2}\right)$, and water vapor $\left(\mathrm{H}_{2} \mathrm{O}\right)$. Of the above processes, oxidation is by far the most exothermic. At low temperatures, oxygen consumption can be expressed by the following equation [17]:

$$
\text { Rate }=A\left[\mathrm{O}_{2}\right]^{n} \exp \left(\frac{-E}{R T}\right),
$$

where $E$ is the activation energy, which for different coals can vary from 12 to $95 \mathrm{~kJ} / \mathrm{mol}$; $A$ is the preexponential factor, which is typically between 1 and $7 \times 10^{5} / \mathrm{s}$ and depends on the coal rank and measurement method; $R$ is the gas constant; $n$ is the apparent order of reaction; $T$ is the absolute temperature; and $\left[\mathrm{O}_{2}\right]$ is the oxygen concentration.
TABle 1: Physical and chemical parameters of the coal.

\begin{tabular}{lc}
\hline Density of the coal $\left(\mathrm{kg} \cdot \mathrm{m}^{3}\right)$ & 1300 \\
Activation energy $(\mathrm{Kj} /(\mathrm{mol} \cdot \mathrm{K}))$ & 90.0 \\
Thermal conductivity of coal W/(m·K) & 0.1998 \\
Heat release when coal absorbs one Moore oxygen & 310 \\
$(\mathrm{Kj})$ & 64 \\
Preexponential factor $\left(\mathrm{s}^{-1}\right)$ & 300 \\
Initial temperature $(\mathrm{K})$ & 1003 \\
Specific heat capacity $\left(\mathrm{J} \cdot \mathrm{kg}^{-1} \cdot \mathrm{K}\right)$ & \\
\hline
\end{tabular}

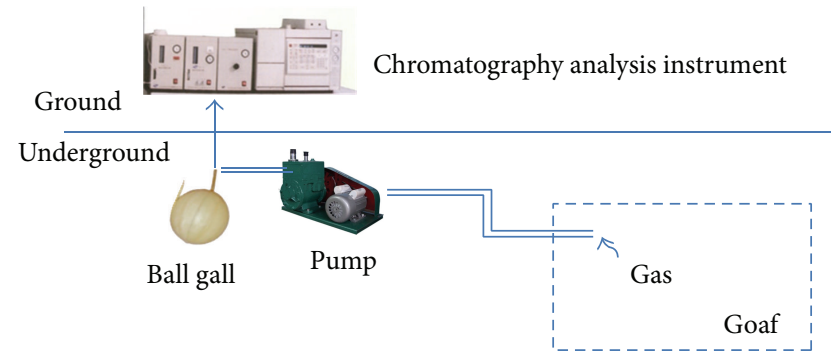

FIGURE 2: Collection of gas from the goaf for oxygen concentration analysis.

According to the Arrhenius equation (Equation (8)), the temperature will have a large influence on oxygen consumption. Therefore, to accurately describe the oxygen concentration, the heat of the coal oxidation reaction at low temperatures must be considered. This heat can be expressed by $Q=V q$, where $Q$ is the exothermic velocity, which is closely related to the oxygen consumption, and $q$ is total heat release for consumption of one mole of oxygen at low temperature by coal oxidation. In this paper these chemical reaction parameters of the coal can be seen as in Table 1 .

\section{In Situ Measurement and Model Configuration}

3.1. Field Experiment on Oxygen Concentration in Goaf. For calibration and to validate the simulation results, mixed gas samples were collected from the goaf (Figure 2) in an actual coal mine and analyzed by gas chromatography (GC) to obtain the oxygen concentration. To collect these samples, multiple sample collection tubes were placed in the goaf behind the scraper conveyor.

The gas from the goaf was collected through these tubes using a pump and pumped into a ball sample vessel. This full sample vessel was transferred to the laboratory for analysis.

The pump system to remove gas from the goaf using suction was an electric rotary vane vacuum pump (Figure 3 ) with an explosion-proof motor and power of $0.75 \mathrm{~kW}$. The gas collection tubes were composed of rigid plastic $(\varnothing 8 \mathrm{~mm})$ that could withstand negative pressure. The tubes were also placed in a seamless steel tube for further protection against damage from falling rocks in the goaf (Figure 4(a)). A sealant of latex clay was placed between the tubes and the protective sleeve 


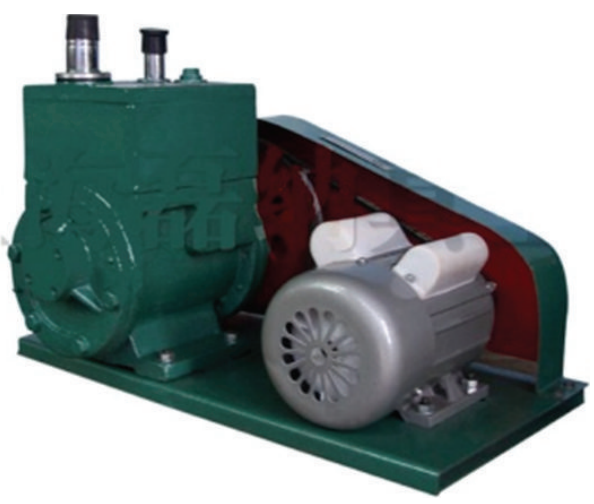

FIGURE 3: Electric rotary vane vacuum.

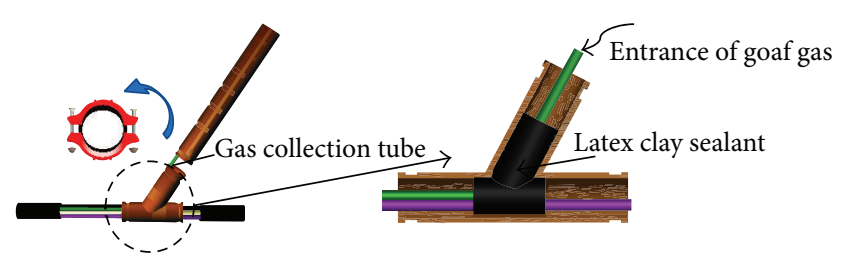

(a)

(b)

Figure 4: (a) Protective sleeve around gas collection tube. (b) Placement of latex clay sealant in protective sleeve.

(Figure 4(b)), to ensure that the extracted gas originated from the goaf and not from the protective sleeve.

Gas samples were collected at three different points in the mine (Figure 5). Collection tubes were placed in the goaf near the air return, air inlet, and $60 \mathrm{~m}$ from the air return. The workface in this area is ventilated at $1400 \mathrm{~m}^{3} / \mathrm{min}$ with fresh air with the following composition (percentage by volume): oxygen $(20.7 \%)$, and nitrogen $(80.6 \%)$. The gas samples were analyzed using a KSS-200 chromatograph. This system can be used to analyze the following gases (volume fraction ranges): $\mathrm{O}_{2}(0-25 \%) ; \mathrm{N}_{2}(70-98 \%) ; \mathrm{CO}, \mathrm{C}_{2} \mathrm{H}_{4}, \mathrm{C}_{2} \mathrm{H}_{6}$, and $\mathrm{C}_{2} \mathrm{H}_{2}(0-50 \%)$; and $\mathrm{CH}_{4}$ and $\mathrm{CO}_{2}(0-80 \%)$. This system has an accuracy of $\leqslant 1 \mathrm{ppm}$ and relative error of $\leqslant 1.5 \%$.

\subsection{Model for Simulation of Oxygen Concentration in the Goaf} under Gas Drainage Conditions. Boundaries for the model were based on a workface in Dafosi coalmine (China), which has a U-type ventilation mode. Figure 6 shows the layout for the CFD model based on the Dafosi coalmine workface. The intake airflow and return airflow are shown in red on the right and left, respectively, of the front of this model. A gas drainage system was established in the model, which included a gas drainage pipe near the return airflow (Point 1 in Figure 6) and gas drainage boreholes in the goaf (Point 2 in Figure 6). The length of the workface which is also the goaf width in the model was $200 \mathrm{~m}$, and the distance from the starting point of the longwall to the workface was $500 \mathrm{~m}$. The height of the goaf flow field was $20 \mathrm{~m}$, the coal seam pitch was $0^{\circ}$, the pitch in the strike direction was $2^{\circ}$, and the workface was ventilated in $U$ $+\mathrm{L}$-mode. Air ventilation was at a rate of $1400 \mathrm{~m}^{3} / \mathrm{min}$ with

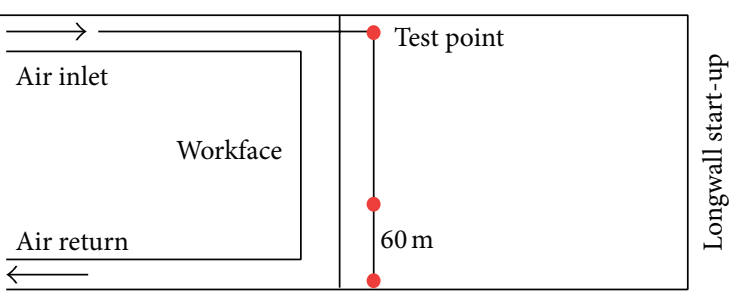

FIGURE 5: Gas collection points in the coalmine.

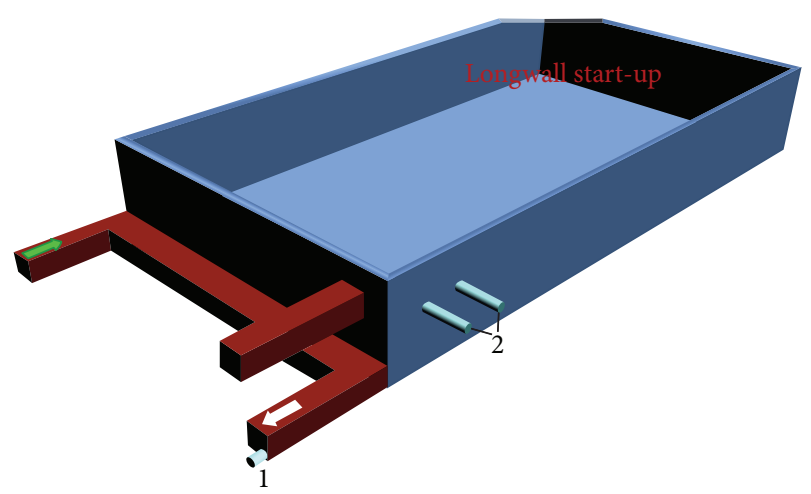

Figure 6: Model for gas drainage from the goaf through (1) a gas drainage tube in the area of the return airflow and (2) gas drainage boreholes in the goaf.

TABLE 2: Parameters of the workface and goaf.

\begin{tabular}{lc}
\hline Goaf size $(\mathrm{m})$ & $500(\mathrm{~L}) \times 200(\mathrm{~W}) \times 20(\mathrm{H})$ \\
Section size of workface $(\mathrm{m} \times \mathrm{m})$ & $3(H) \times 8(\mathrm{~W})$ \\
Wind volume of workface $\left(\mathrm{m}^{3} / \mathrm{min}\right)$ & 1400 \\
Oxygen concentration of the wind & $20.7 \%$ \\
Coal seam pitch $\left(^{\circ}\right)$ & 0 \\
Strike pitch $\left(^{\circ}\right)$ & 2 \\
Section size of laneway $(\mathrm{m} \times \mathrm{m})$ & $4(\mathrm{~W}) \times 3(\mathrm{H})$ \\
Diameter of drainage pipe $1 \mathrm{and}$ pipe & 325 \\
$(\mathrm{~mm})$ & 200 \\
Gas drainage rate of pipe $1\left(\mathrm{~m}^{3} / \mathrm{h}\right)$ & 180 \\
Gas drainage rate of pipe $2\left(\mathrm{~m}^{3} / \mathrm{h}\right)$ & \\
\hline
\end{tabular}

an oxygen volume fraction of $20.7 \%$. The gas drainage pipe at Point 1 had a diameter of $325 \mathrm{~mm}$, and the gas drainage rate was $200 \mathrm{~m}^{3} / \mathrm{h}$. Gas drainage from the boreholes in the goaf was at a rate of $180 \mathrm{~m}^{3} / \mathrm{h}$. The gas that was drained from the goaf main mainly came from the workface and bottom and roof of the goaf. Assuming that gas emission had a linear relationship, the gas release from the goaf was predicted to be about $21-24 \mathrm{~m}^{3} / \mathrm{min}$ in this model. Main parameters of this model can be seen as in Table 2.

The model was meshed using an unstructured grid containing about 84000 cells and 179000 faces (Figure 7(a)). For the model to converge easily during the solving process, the mesh was increased around where the gas drainage boreholes were located (Figure 7(b)). 


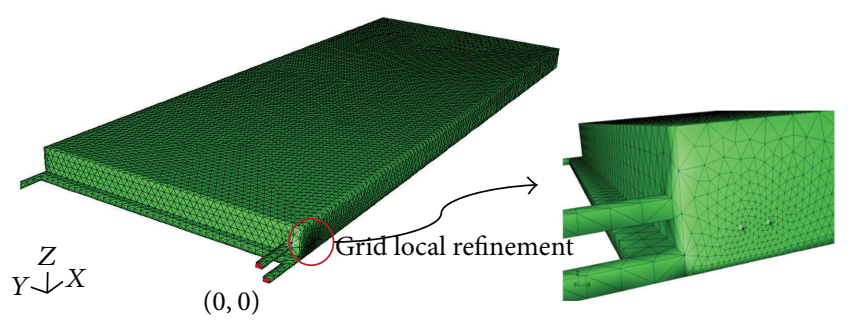

(a)

(b)

Figure 7: CFD model geometry and computational grid of a longwall panel.

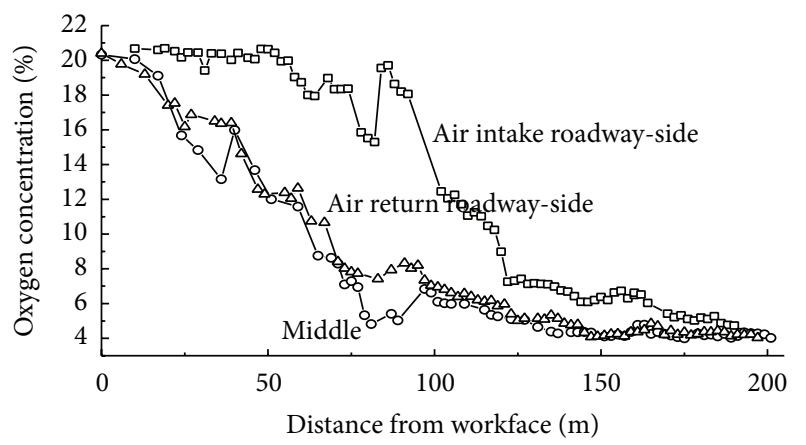

Figure 8: Percentage by volume of oxygen in the goaf.

\section{Results and Discussion}

4.1. Oxygen Concentrations in the Mine Goaffrom Field Study. The oxygen concentration in the goaf was very high beside the air inlet (Figure 8). In this area the volume fraction of oxygen in the goaf remained $>18 \%$ until $70 \mathrm{~m}$ behind the long-wall workface and $>8 \%$ until $120 \mathrm{~m}$ behind the longwall workface. In the middle of the goaf, $60 \mathrm{~m}$ from the air-return, the volume fraction of oxygen in the goaf remained at $>18 \%$ until $20 \mathrm{~m}$ behind the workface and at $>8 \%$ until $75 \mathrm{~m}$ behind the longwall workface. The trends in the reduction of oxygen in the goaf were very similar in these two areas.

\subsection{Simulation Results and Discussion}

4.2.1. Oxygen Concentration in the Goaf under Gas Drainage Conditions. The distribution patterns of oxygen in the goaf obtained with the model are illustrated in Figures 9 and 10. The gas at higher levels above the bottom of the goaf has a lower oxygen concentration (Figure 10). The oxygen concentration at different distances from the workface was also obtained with the model (Figure 11). It presented similar trends in the oxygen concentration as observed in the field study (Figure 8). This suggests that the simulation can reflect the actual gas distribution in goaf. Comparison of temperature anomalies between the presented simulation results and in situ measurements is only possible when the overlying beds are assumed to be homogeneous on a macroscopic scale.
Consequently, the results do not necessarily apply to all fire sites.

At $20 \mathrm{~m}$ above the bottom of the goaf, the air inlet region was the only area where the volume fraction of oxygen was $>20 \%$. At this height, the volume fraction of oxygen was only $15 \%$ near the air return.

Figure 12 shows the oxidation zone or coal spontaneous combustion zone obtained from the model. This zone is defined as the area where the oxygen volume fraction is 8$18 \%$. On the air inlet-side, float coal dust $75 \mathrm{~m}$ from the workface will be in the spontaneous combustion zone, and that at $130 \mathrm{~m}$ from the workface will be in the suffocation zone. In the middle area of the goaf, the float coal dust will be in the spontaneous combustion zone at only $30 \mathrm{~m}$ from the workface and in the suffocation zone at $67 \mathrm{~m}$ from the workface. Near the air return, float coal dust is in the spontaneous combustion and suffocation zones at $26 \mathrm{~m}$ and $72 \mathrm{~m}$, respectively, from the workface. Because fully mechanized caving mining creates large quantities of float coal dust in the goaf, the thickness of float coal dust will always be sufficient for coal spontaneous combustion. Therefore, the spontaneous combustion zone in the model is equivalent to the hazard zone for the mine. The maximum width of the spontaneous combustion hazard zone is $55 \mathrm{~m}$ near the intake airflow. The simulation showed that there is a serious air leak at the workface of the goaf in this mine; even with high methane release, high oxygen concentrations were widespread.

Figure 13 presents a three-dimensional representation of the spontaneous combustion zone. In this figure, blue represents an oxygen volume fraction of $8 \%$, and orange represents an oxygen volume fraction of $18 \%$.

Because oxygen density is higher than air density, the oxygen concentration near the bottom of the goaf was higher than that in the upper part of the goaf close to the workface (Figures 14 and 15). This suggests the possibility of coal spontaneous combustion is higher in the upper part of the goaf than near the bottom. Further from the workface, the possibility of coal spontaneous combustion was lower in the upper part of goaf than near the bottom.

The CFD simulation indicated that the high oxygen region was widespread in the goaf, which could increase coal spontaneous combustion. To prevent this, the fire control measures for the mine must be improved. Consequently, three-phase foam was used during backfilling of the goaf. Three-phase foam has a large flow volume, excellent fluidity, and low density, is durable, and provides uniform coverage.

\subsubsection{Effect of Gas Drainage Volume on Oxygen Distribution.} In order to study the effect of gas drainage parameters on spontaneous combustion, the gas drainage volume was changed and the oxygen distribution in goaf was simulated again. Gas drainage from three points was investigated. These points were (1) $5 \mathrm{~m}$ behind the workface and $5 \mathrm{~m}$ from the goaf boundary near the air return, (2) $5 \mathrm{~m}$ behind the workface and $5 \mathrm{~m}$ from the goaf boundary near the air intake, 

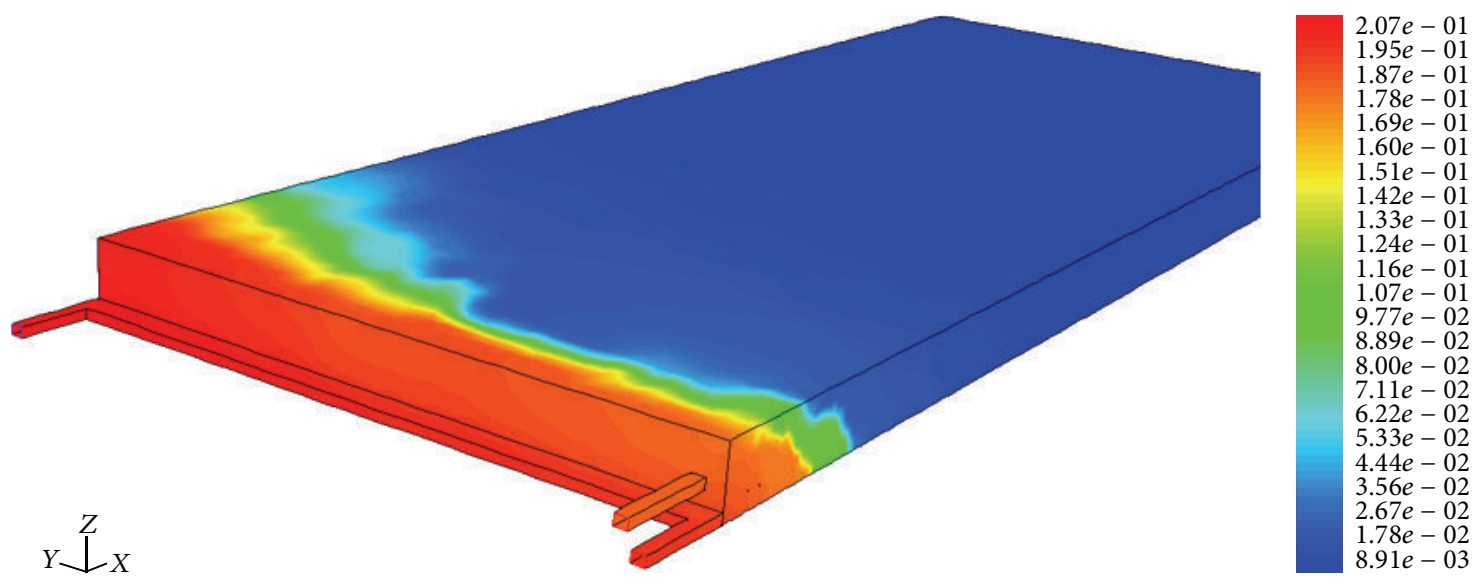

FIGURE 9: Oxygen on the surface of the model.

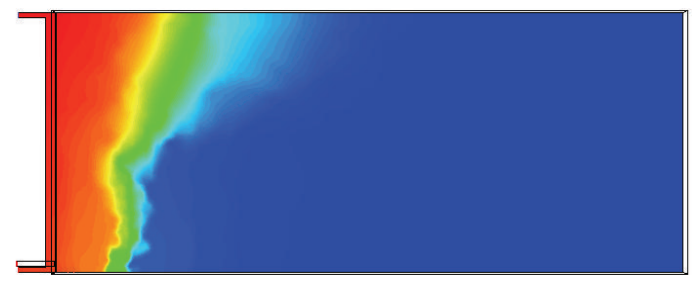

Cloud picture of oxygen concentration (bottom)

(a)

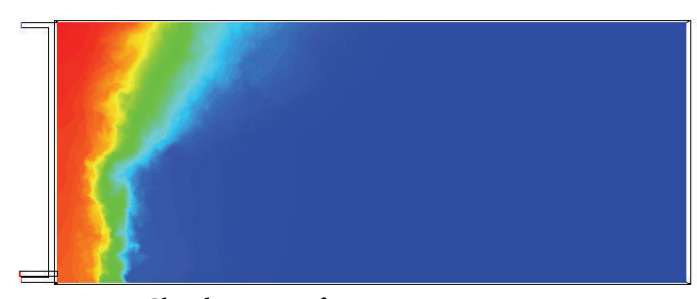

Cloud picture of oxygen concentration (10 $\mathrm{m}$ above bottom)

(c)

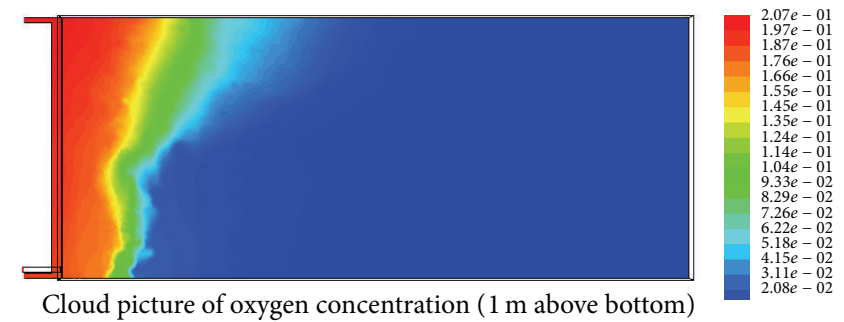

(b)

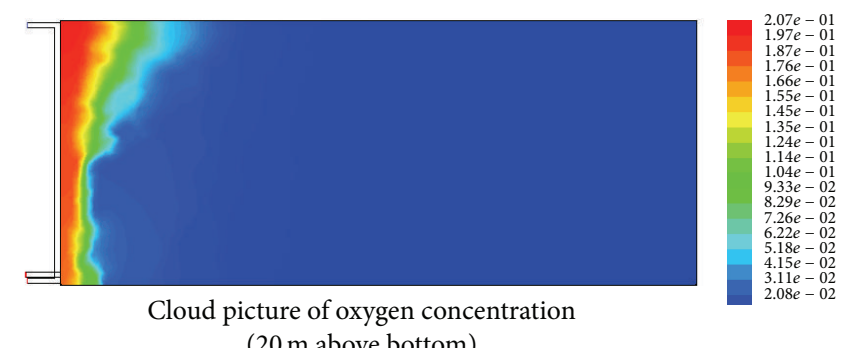
(20 $\mathrm{m}$ above bottom)

(d)

FIGURE 10: Oxygen distribution at different levels in the goaf: (a) the bottom, (b) $1 \mathrm{~m}$ above the bottom, (c) $10 \mathrm{~m}$ above the bottom, and (d) $20 \mathrm{~m}$ above the bottom.

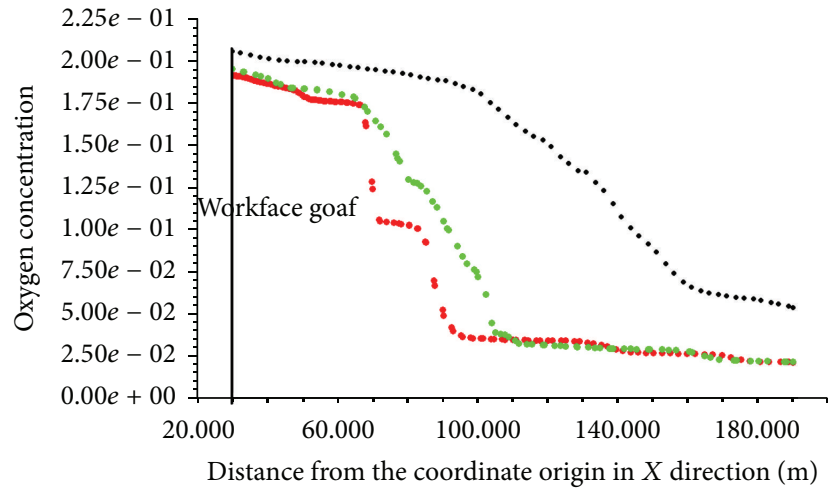

FIGURE 11: Oxygen concentration at different distances from the workface. 


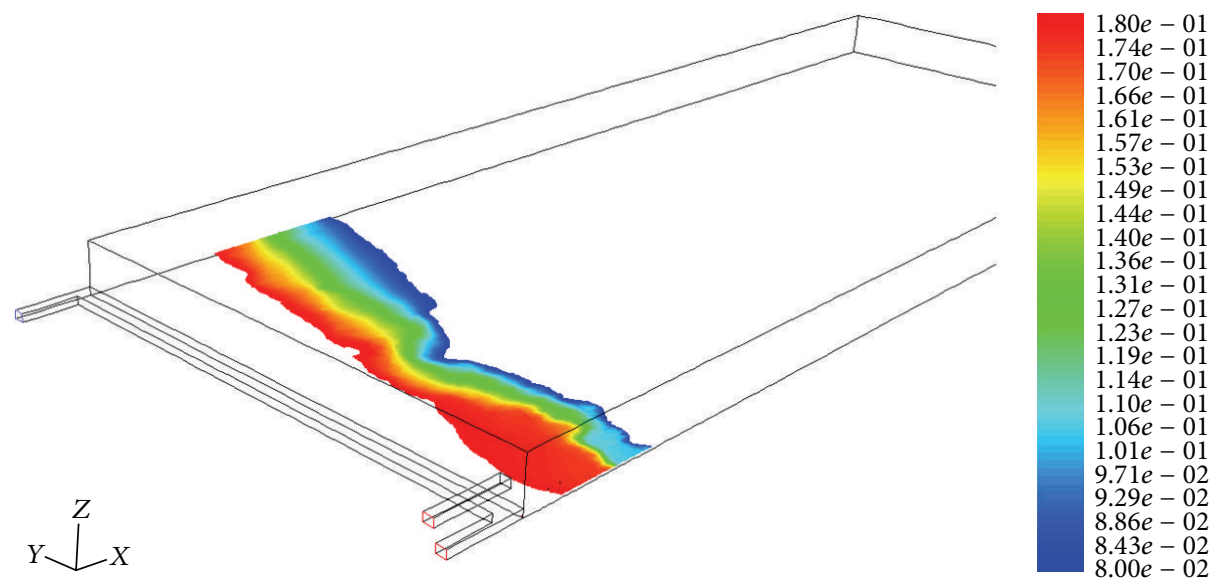

FIGURE 12: Oxidation zone or coal spontaneous combustion zone.

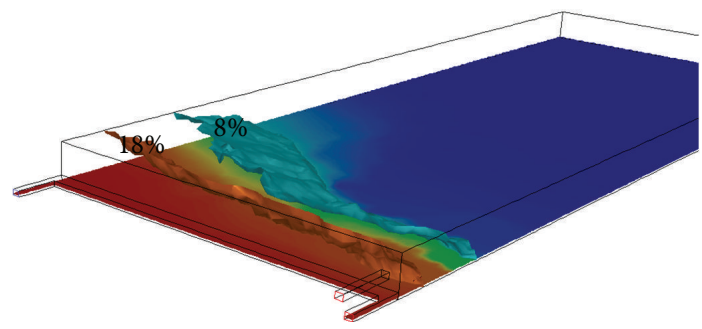

FIGURE 13: Three-dimensional distribution of spontaneous combustion zone.

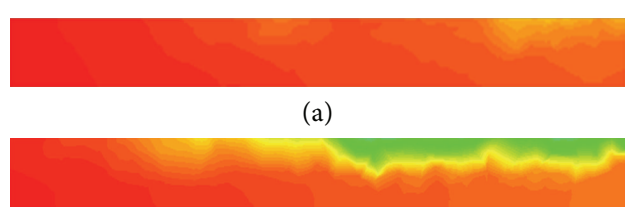

(b)

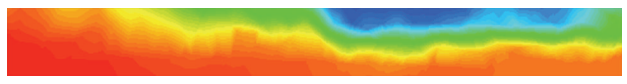

(c)

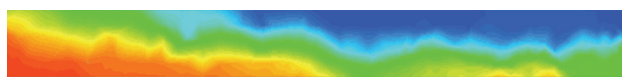

(d)

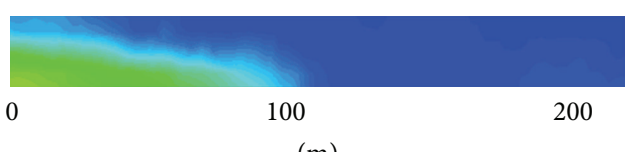

$(\mathrm{m})$

(e)

FIgURE 14: The oxygen distribution in section planes (a) $10 \mathrm{~m}$, (b) $20 \mathrm{~m}$, (c) $30 \mathrm{~m}$, (d) $50 \mathrm{~m}$ and (e) $80 \mathrm{~m}$ behind the workface.

and (3) $50 \mathrm{~m}$ behind the workface and $100 \mathrm{~m}$ from the goaf boundary, and all of these points are on the goaf bottom.

Figure 16 shows the changes in the volume fraction of oxygen at Points 1-3 with different drainage volumes for

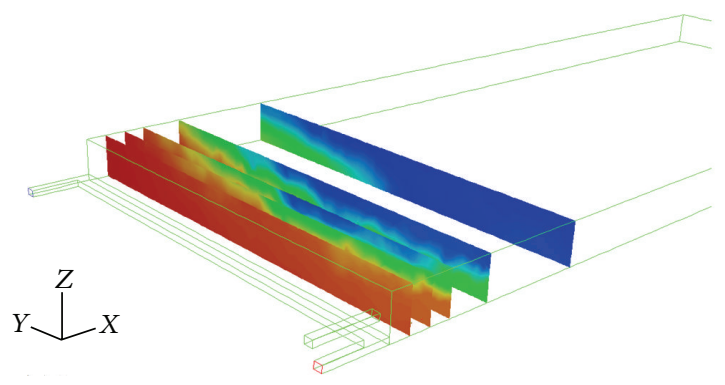

FIGURE 15: Location of longitudinal sections.

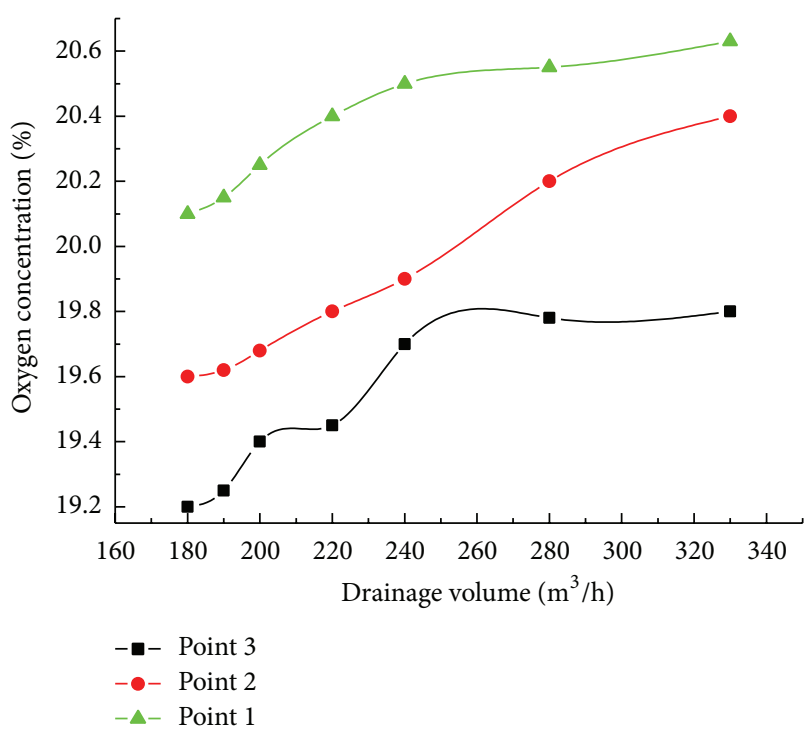

FIGURE 16: Effect of the gas drainage volume in pipe 1 on the concentration of oxygen at Point 1, Point 2, and Point 3.

gas drainage pipe 1 . The variation in the volume fraction of oxygen was dependent on the goaf gas drainage volume. Larger gas drainage volumes resulted in increased leakage that is why volume fractions of oxygen at the three points 


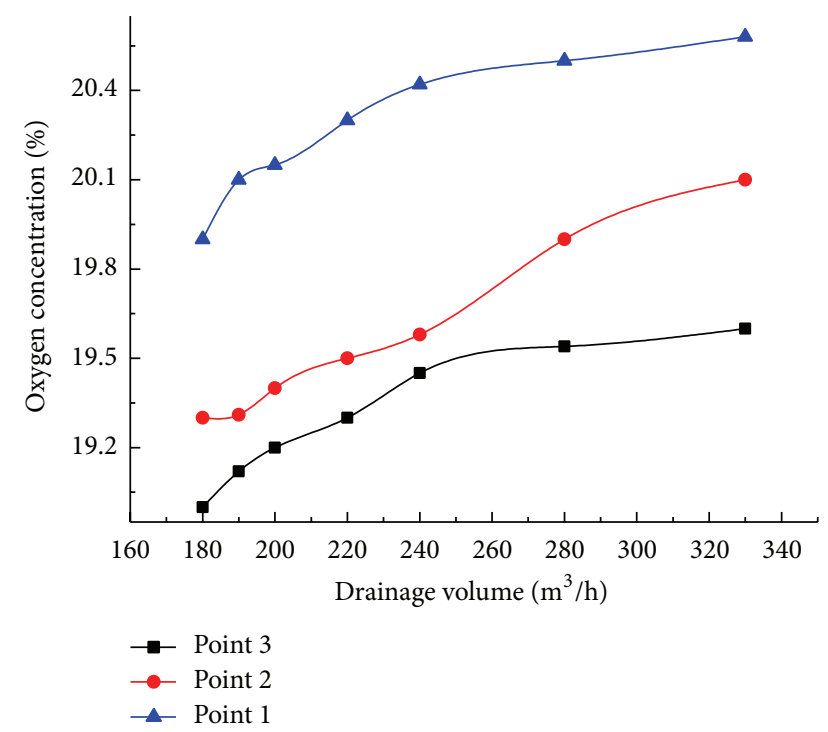

FIGURE 17: Effect of the gas drainage volume in pipe 2 on the concentration of oxygen at Point 1, Point 2, and Point 3.

become higher. However, the oxygen concentration at Point 3 increased slightly faster than at Point 1 or 2 . This suggests that increases in the gas drainage volume create greater risk of coal spontaneous combustion on the air return side than on the air intake side or in the middle of the goaf.

Figure 17 shows the changes in the volume fraction of oxygen at Points 1-3 with different drainage volumes for gas drainage pipe 2. From this figure we can also find that the variation in the volume fraction of oxygen was dependent on the goaf gas drainage volume. Larger gas drainage volumes resulted in higher oxygen concentration. Besides, from the contradistinction between Figures 16 and 17, we can find that, with the same drainage volume, when there is drainage of the gas from the pipe 1, oxygen concentration is higher; it means that drainage from the pipe 1 may lead to higher possibility of coal spontaneous combustion. So if we must use drainage of gas from the goaf, we would better use drainage of gas at the location of pipe 2 rather than pipe 1.

\section{Conclusions}

In combination with detailed field studies, extensive CFD modeling was conducted to investigate the oxygen distribution in longwall goaf under gas drainage conditions. The results of these studies greatly improve the fundamental understanding of the distribution of oxygen and other gases in coalmines. The high oxygen region in the mine was widespread in the goaf under gas drainage conditions. Near the air inlet, the maximum width of the spontaneous combustion zone was about $70 \mathrm{~m}$. The gas drainage volume influenced the oxygen concentration in the goaf, with greater volumes of gas drainage increasing the volume fraction of oxygen. The oxygen was more concentrated near the air return than near the air intake or the middle of the goaf. In comparison to field study results, the CFD simulation of the oxygen distribution in the mine was an accurate representation of the actual situation in the goaf under gas drainage conditions. This method is flexible and simple to conduct and can be used to numerically simulate various complex situations of spontaneous combustion. The results provide a means for control of spontaneous combustion and establishment of firefighting measures in coalmines.

\section{Conflict of Interests}

The authors declare that there is no conflict of interests regarding the publication of this paper.

\section{Acknowledgments}

This research was supported by the National Natural Science Foundation of China (Grant nos. 51106175, 51134020, and 51104154), Fundamental Research Funds for the Central Universities(2011QNA05) and China Postdoctoral Science Foundation funded project.

\section{References}

[1] X. C. Li, Coal Mine Safety in China, China Coal Industry Press, Beijing, China, 1998 (Chinese).

[2] A. K. Singh, R. V. K. Singh, M. P. Singh, H. Chandra, and N. K. Shukla, "Mine fire gas indices and their application to Indian underground coal mine fires," International Journal of Coal Geology, vol. 69, no. 3, pp. 192-204, 2007.

[3] A. Saghafi, N. W. Bainbridge, and J. N. Carras, "Modelling of spontaneous heating in a longwall goaf," in Proceedings of the 7th US Mine Ventilation Symposium, pp. 167-172, June 1995.

[4] A. Saghafi and J. N. Carras, "Modeling of spontaneous combustion in underground coal mines: application to a gassy longwall panel," in Proceedings of the 27th International Conference of Safety in Mines Research Institute, pp. 573-579, 1997.

[5] R. Balusu, G. Deguchi, R. Holland et al., "Goaf gas flow mechanics and development of gas and Sponcom control strategies at a highly gassy mine," Coal and Safety, vol. 20, no. 3, pp. 35-45, 2002.

[6] A. C. Smith and C. P. Lazzara, "Spontaneous combustion studies of US coals," Report of Investigations 9079, US Bureau of Mines, 1987.

[7] L. Yuan and A. C. Smith, "Numerical study on effects of coal properties on spontaneous heating in longwall gob areas," Fuel, vol. 87, no. 15-16, pp. 3409-3419, 2008.

[8] A. C. Smith, Y. Miron, and C. P. Lazzara, "Large-scale studies of spontaneous combustion of coal," Report of Investigations 9346, US Bureau of Mines, Washington, DC, USA, 1991.

[9] J. Bear, Fluid Dynamics in Porous Medium, Press of China Building Industry, Beijing, China, 1983.

[10] F. J. Wang, Principle and Application of CFD Software, Tsinghua University Press, Beijing, China, 2004.

[11] Z. Wen, L. C. Shi, and Y. R. REN, Course Book of Fluid Calculation by FLUENT, Tsinghua University Press, Beijing, China, 2004.

[12] D. P. Creedy and R. D. C. Clarke, "Minimizing firedamp risks on high production coalfaces: a computational modelling approach," in Proceedings of the International Symposium: Safety, Hygiene and Health in Mining, pp. 192-203, 1992. 
[13] T. X. Ren, J. S. Edwards, and R. R. Jozefowizc, "CFD modeling of methane flow around Longwall coal faces," in Proceedings of the 6th International Mine Ventilation Congress, pp. 17-22, 1997.

[14] T. X. Ren and J. S. Edwards, “Three-dimensional computational fluid dynamics modelling of methane flow through permeable strata around a longwall face," Mining Technology, vol. 109, no. 1, pp. 41-48, 2000.

[15] Q. T. Hu, Y. P. Liang, and J. Z. Liu, "CFD simulation of methane flow in goaf," Journal of Coal science and Engineering, vol. 32, no. 7, pp. 719-724, 2007.

[16] J. N. Carras and B. C. Young, "Self-heating of coal and related materials: models, application and test methods," Progress in Energy and Combustion Science, vol. 20, no. 1, pp. 1-15, 1994.

[17] L. Yuan and A. C. Smith, "Computational fluid dynamics modeling of spontaneous heating in Longwall gob areas," Transactions of the Society for Mining, Metallurgy, and Exploration, vol. 322, p. 37, 2007. 


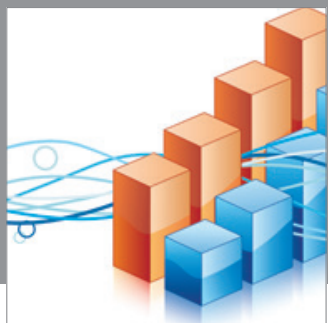

Advances in

Operations Research

mansans

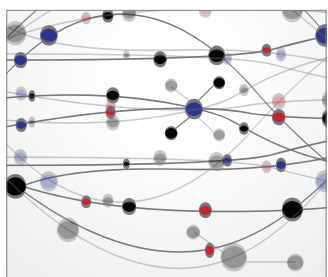

The Scientific World Journal
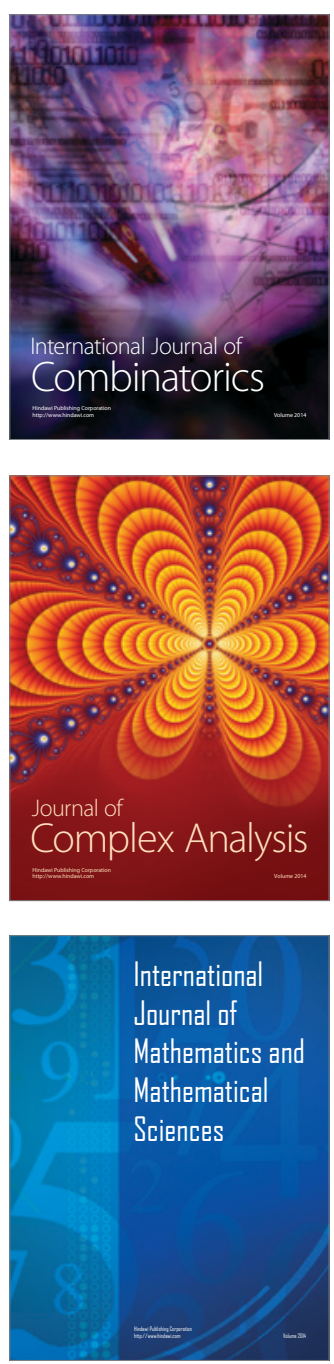
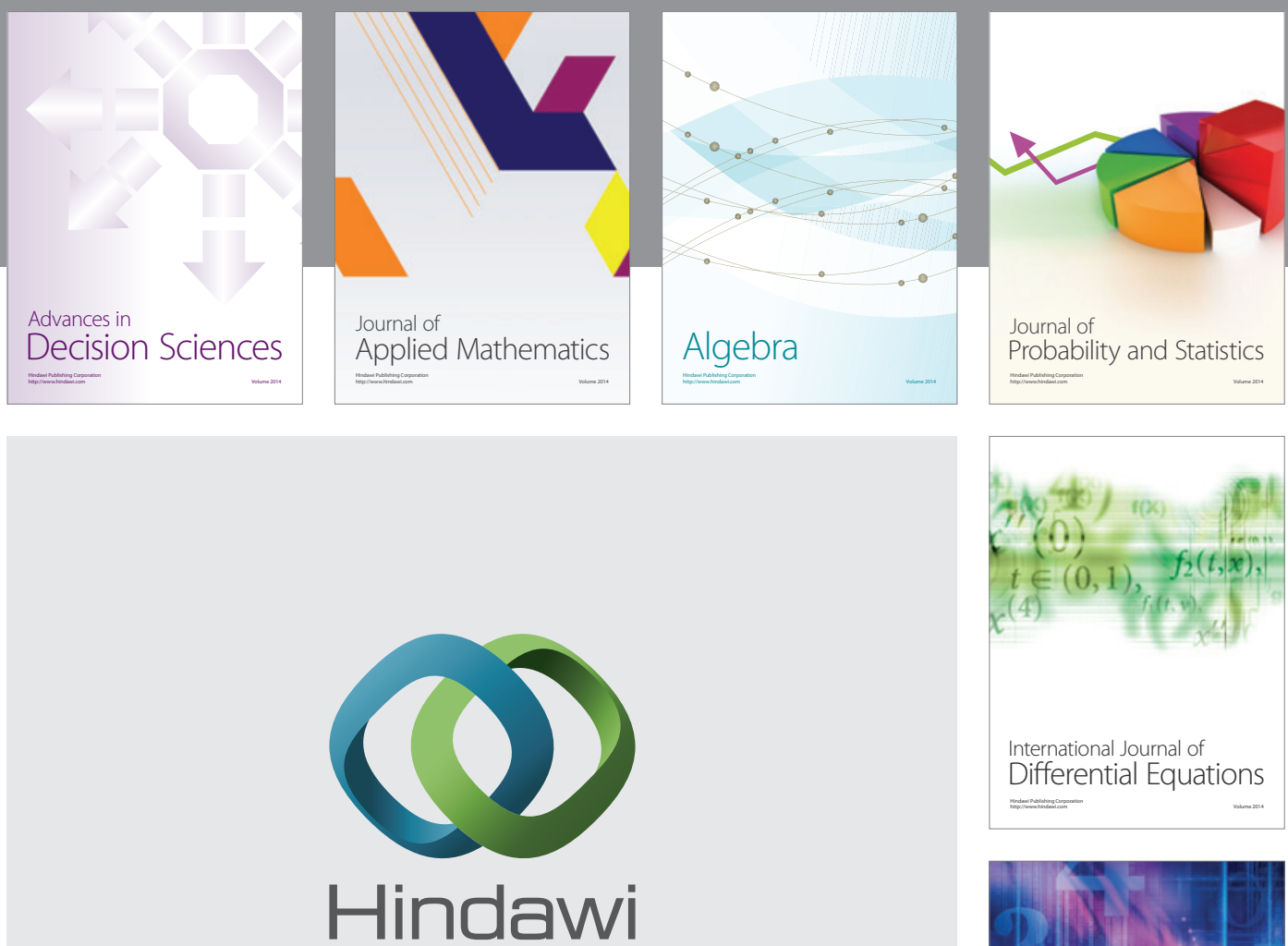

Submit your manuscripts at http://www.hindawi.com
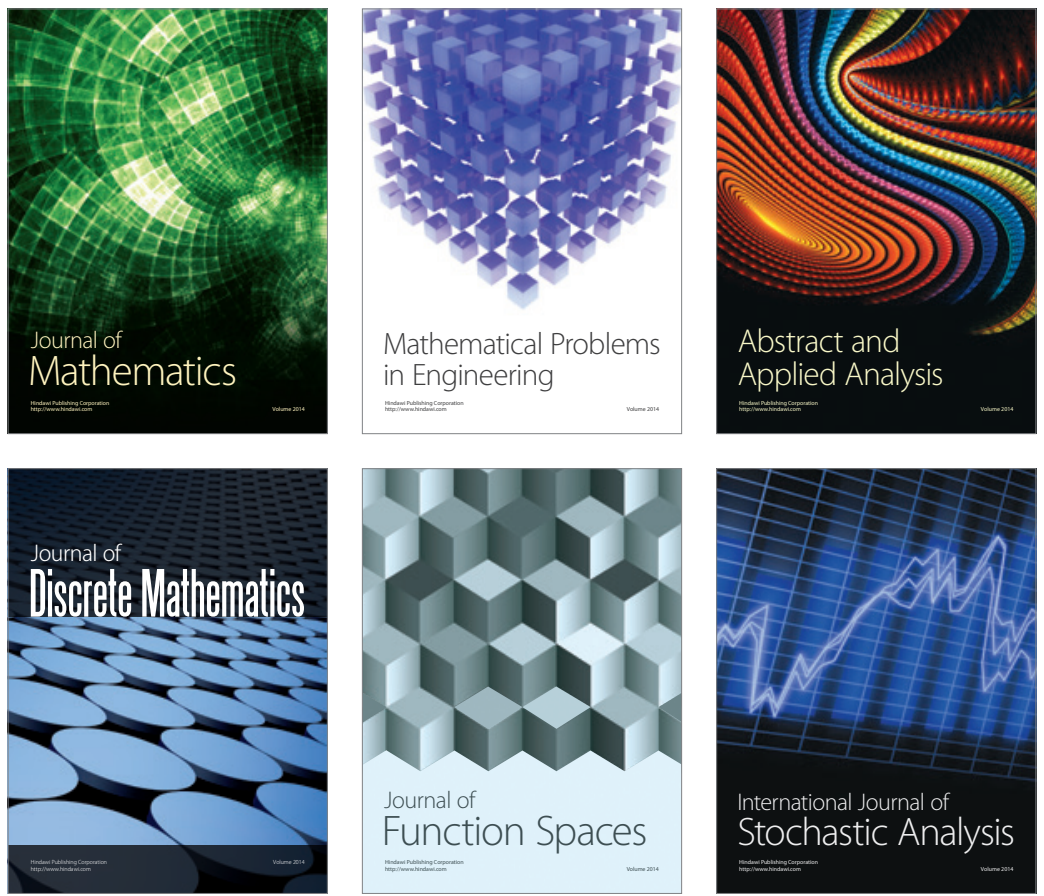

Journal of

Function Spaces

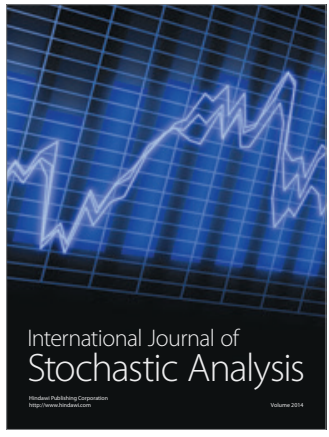

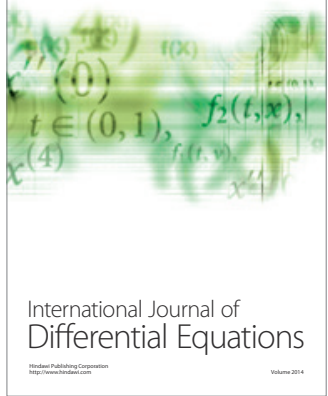
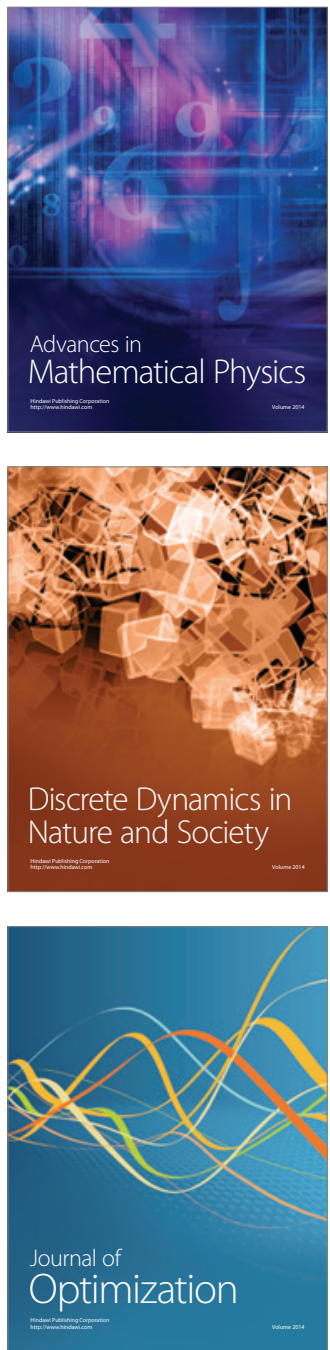